\title{
POR UMA EDUCAÇÃO EMANCIPADORA EM TEMPOS DE CULTURA MERCANTILIZADA: O MST E A OCUPAÇÃO DA ESCOLA COMO ESPAÇO DE TRANSFORMAÇÃO E DESENVOLVIMENTO SOCIOCULTURAL PARA TODA A COMUNIDADE*
}

\author{
Rodrigo Dias Araujo ${ }^{1}$ \\ Marisa Noda ${ }^{2}$
}

\section{Introdução}

Na contemporaneidade debate-se a Educação e aponta-se o seu caráter reprodutivista dentro da lógica do sistema produtivo capitalista. A gestão e o planejamento educacional no Brasil sempre estiveram e estão condicionados a função social da escola em seus respectivos contextos, interferindo diretamente na elaboração de uma educação básica de qualidade para todos, sendo observado um processo de meandros promovido por diversos atores, movidos por muitos interesses e em diferentes períodos. O referido texto tem como objetivo abordar a dificuldade de criação e implantação de propostas de uma educação emancipadora no contexto da sociedade moderna. Para tal, torna-se essencial tecer alguns apontamentos sobre a função social da escola, a formatação dos sujeitos perante uma cultura mercantilizada e a alienação do indivíduo no processo produtivo e nas transformações sociais acentuadas por meio da tecnologia. Ademais se apresenta o histórico e a proposta de ocupação da escola promovida pelo Movimento dos Trabalhadores Rurais Sem Terras (MST)

\footnotetext{
${ }^{*}$ DOI - 10.29388/978-65-86678-78-9-0-f.25-42

${ }^{1}$ Mestrando do Programa de Pós-Graduação em Educação - Mestrado Profissional em Educação Básica

${ }^{2}$ Professora do Programa de Pós-Graduação em Educação - Mestrado Profissional em Educação Básica.
} 
como uma perspectiva contra-hegemônica na busca pelas mudanças socioculturais almejadas pela Educação.

\section{Função social da escola e cultura mercantilizada}

O período monárquico brasileiro até a contemporaneidade neoliberal, a escola, toma corpo e funções determinantes para a formação dos sujeitos desejáveis para cada período, para transformação ou manutenção da ordem vigente e para a construção de um espírito coletivo ou individualizado conforme as demandas da classe dominante vigente e as novas configurações dos sistemas produtivos.

No artigo de Maria Angélica Cardoso e Ângela Mara de Barros Lara (2009) as autoras identificam as funções sociais da escola sob a perspectiva de cinco autores: Bourdieu (1999) nos explicita a escola conservadora, no qual a função social da escola está na conservação das desigualdades e da reprodução das classes sociais, acrescentando que esta instituição, tal como está organizada, não promoverá uma transformação profunda na sociedade. Pérez Gómez (1998) relata a escola como um cenário de conflitos e contradições, como uma instituição socializadora das novas gerações ao mesmo que cumpre a função de reprodução social choca-se com a lógica de quebrar os caracteres sociais, especialmente para grupos menos favorecidos. Desta forma, vê, na escola, um espaço no qual a função reprodutivista pode ser quebrada pela priorização da função educativa. Dermeval Saviani (1980/83) descreve a educação como promotora do homem, destacando que a função social da escola é promover o homem, elaborando, a partir daí, um método que permitiria à escola exercer tal função; principalmente pautado na formação crítica e qualitativa dos seus docentes.

Gramsci (1979) propõe a escola unitária e desinteressada, tecendo uma crítica ao modelo clássico e profissionalizante; para o autor tal perspectiva deveria assumir a função de elevar o grau de maturidade e capacidade dos jovens e inseri-los na atividade social, pautada na autonomia e na iniciativa; a escola criaria um nivelamento nas condições entre camadas sociais, diminuindo as diferenças culturais. Alves (2001) discorre como as funções reprodutivista e 
pedagógica foram para segundo plano, perpassando desde a concepção de uma escola para conservar as desigualdades e reproduzir as classes sociais até a escola que conduz o aluno ao hábito de estudo, propõe a análise, o raciocínio e a abstração.

Nagel (2011) considera que cada época está presa a engrenagens próprias, tecendo considerações sobre o cidadão desejado em diversos contextos históricos e socioeconômicos, explorando desafios e perspectivas. Com a queda do Império e a transição para a Primeira República, por exemplo, a necessidade de organizar o trabalho após a abolição da escravatura e o contexto de transformar a Federação em um Estado-Nacional, exigia alinhar os valores do perfil educacional e a construção do sujeito brasileiro neste período. A valorização do conhecimento tornou-se um caminho viável num momento de descobertas, conquistas e inovação. Já com o Estado-Nação consolidado e que se industrializava, a burguesia na luta pelo poder e o operariado flertando com o socialismo, necessitava-se de um novo tipo de discurso: a cooperação pelo trabalho e entre os trabalhadores em busca do desenvolvimento econômico do país e a consequente capacidade de satisfazer os anseios de todas as classes sociais. Cabe neste momento à escola a tarefa de regular as necessidades da vida coletiva, reduzindo as concepções de educação e valorizando todo conhecimento envolto a divisão do trabalho.

O pós Segunda Guerra e a desconstrução do Estado-Nação, por sua vez, fazem com que a valorização do homem pelo conhecimento caia por terra, o saber é identificado como forjado, suscetível a manipulação e subserviente a interesses privados, a tecnologia e a percepção de um mundo cada vez com menos necessidade de mão de obra, devido as máquinas, sugerem movimentos de negação do saber já construído e adotado, sendo a educação delegada a função de desconstrução do conhecimento já estabelecido para proporcionar o desenvolvimento. Sobre a pós-modernidade Nagel (2011) reflete

Dos pressupostos pedagógicos básicos da atualidade - como: a) defesa constante da autonomia do aluno; b) aconselhamento de tolerância para com os discentes; d) entendimento de aprendizagem como aventura criadora de cada sujeito; d) percepção de conteúdos de ensino como coer- 
ção e/ou inutilidade; e) afirmação da educação como troca de experiência e f) da escola como lugar de encontro - nenhum deles, sozinhos ou tomados no seu conjunto, permitirá que se vislumbre outra resposta diferente à já dada: a escola atual é decodificada como uma agremiação de pessoas iguais e democráticas que se dispensaram de qualquer processo de transformação de si mesmas ou do desejo de mudanças qualitativas na sociedade. (NAGEL, 2011, p. 9)

Cunha (2007) analisa o processo de privatização da educação brasileira e o caracteriza como um processo que percorre entre o incentivo ao crescimento ora do setor público, ora do setor privado, ora de ambos. $\mathrm{O}$ autor nos evidencia a dificuldade de se construir ou implementar um sistema educacional de qualidade devido a configuração conflituosa entre público e privado, cujo privado está a cada dia mais engendrado ao público, seja na influência exercida por grandes corporações ou instituições internacionais ou por representantes de interesses privados dentro de departamentos ou órgãos colegiados no setor público que influenciam a tomada das decisões.

Michael Young (2007) complementa o debate expressando as tensões e conflitos entre demandas políticas e realidades educacionais que permeiam o papel social da escola, fazendo do ambiente escolar um campo de batalha. Palangana (1998) debate em sua obra as modificações sofridas pelos indivíduos pelo modo de organização do trabalho e as transformações culturais recorrentes da transnacionalização do capital e o desenvolvimento dos meios de comunicação em massa e a individualização na contemporaneidade.

Nagel (2010) ressalta que a descrença na possibilidade de transformar, ou educar, é a expressão da consciência a-histórica que vem sendo impregnada nos indivíduos, desta forma a economia se põe a formatar o homem, enquanto a educação pensa em personalizá-lo para "ser melhor". Destaca ainda que nas sociedades consumistas constitui-se uma autossatisfação potencializada que substitui qualquer disponibilidade para a consciência e prática política. O ser social então só se percebe pelo consumo.

Crochik (1998) destaca como as novas tecnologias são utilizadas em nossa sociedade e como tais são implementadas nas escolas representam a 
ideologia da racionalidade tecnológica, aproximada às regras e a lógica do mercado de trabalho, fortalecendo uma consciência que faz a leitura da realidade de forma técnica e sistêmica e limita a percepção das contradições da realidade, delegando que as inovações tecnológicas por si só liberte a sociedade de suas injustiças e negando a libertação por meio da consciência social e individual.

Dado este exposto, as transformações sociais ficam cada vez mais comprometidas com os novos sujeitos formatados por esta lógica do capital e da alienação promovida pela divisão do trabalho e muitas vezes reproduzida de forma sistêmica e proposital pelas instituições escolares, seus currículos e modelos de gestão. Denota-se a uma individualidade induzida, pautada na perda da subjetividade do indivíduo, o que gera uma descrença por parte do mesmo em sua capacidade de alterar ordens vigentes e/ou promover mudanças sociais. Mas quem é este indivíduo? Qual é seu contexto histórico e social? Quais são seus anseios pessoais e coletivos? Quais as forças que o constituem? Qual sua autonomia perante a cultura vigente cada vez mais globalizada e implementada nas escolas? Para que servem as escolas? Nota-se a importância de realizar tais provocações para a análise deste artigo.

\section{A ocupação da escola como espaço de transformação}

Valle (2008) nos diz que aspectos de legitimação e hierarquização presentes na sociedade predominam na organização escolar, indicando um sistema educacional cujas raízes estão numa sociedade estruturada por relações sociais desiguais e suas respectivas consequências e manifestações. Nos entanto, as escolas representam ao mesmo tempo espaços de reprodução dessas relações sociais desiguais e espaços de resistências, conflitos e lutas.

No Brasil, os movimentos sociais conotam o ideário de uma educação emancipadora e refutam a lógica global neoliberalista cuja educação está a serviço do mercado, caracterizando uma retomada ao debate da função social da educação e valorizando os contextos locais. Para o Movimento dos Trabalhadores Rurais Sem Terra, democratizar o conhecimento é tão importante quanto à reforma agrária. Desta forma, o movimento, junto a sua luta contra a desi- 
gual distribuição de terras, reivindica desde 1984 o direito à escola pública gratuita e de qualidade em todos os níveis, para todos os indivíduos acampados e assentados.

No início do Movimento, uma luta com a outra não tinha muita relação, mas no decorrer da história do MST, lutar pelo direito à escola integrou-se à reivindicação dessa organização social pela reforma agrária. A luta pelas escolas e, sobretudo para o cultivo do valor dos estudos e do direito ao acesso a eles transformou a luta do MST:

\begin{abstract}
A relação do MST com a educação é, pois, uma relação de origem: a história do MST é a história de uma grande obra educativa. Se recuperarmos a concepção de educação como formação humana é sua prática que encontramos no MST desde que foi criado: a transformação dos 'desgarrados da terra e dos pobres de tudo' em cidadãos, dispostos a lutar por um lugar digno na história. É também educação o que podemos ver em cada uma das ações que constituem o cotidiano de formação da identidade dos sem-terra do MST. (MST, 2004, p. 5).
\end{abstract}

Caldart (2003) analisando a história do MST afirma que ele acabou fazendo uma verdadeira "ocupação da escola", promovida segundo a autora, em três principais sentidos: Primeiro, as famílias sem-terra mobilizaram-se, pelo direito à educação e que a escola tivesse sentido concreto na vida e na realidade da comunidade. No início dos anos 1980, a mobilização iniciou-se pelas mães e professoras, depois ganhou apoio de pais e líderes do Movimento, assim como das próprias crianças beneficiadas. Segundo o MST, dentro de sua própria organicidade, decidiu tomar para si a produção de uma proposta pedagógica específica para suas escolas, e a formação de educadores e educadoras alinhados ao trabalho com tal perspectiva. Criou-se em 1987, o Setor de Educação dentro do Movimento, formalizando intencionalmente esta tarefa assumida. Com a ampliação da escola tanto em seu significado como em sua abrangência, as lutas se estenderam da garantia da educação infantil a universidade, perpassando pela alfabetização do alunato nos acampamentos e assentamentos, a processos de escolarização e formação de militância. Terceiro, o MST in- 
corporou a escola a sua dinâmica: a escola passou a fazer parte do cotidiano e das preocupações das famílias dentro do movimento, consolidada como uma marca cultural. A escola passou a ser vista como uma questão também política, vinculada às estratégias da luta pela reforma agrária e à formação dos sujeitos dentro do movimento. Todo acampamento ou assentamento deve ter uma escola, e esta escola não pode ser "qualquer escola".

A luta pela escola dentro do MST passou de apenas mais uma de suas lutas por direitos sociais, os quais sua própria condição de sem terras os excluía para algo mais amplo. Perceberam que não era uma luta exclusiva do Movimento, já que muitas famílias trabalhadoras do campo e da cidade eram privadas deste direito fundamental.

Percebendo o contexto da educação nacional, o MST abriu espaço em sua agenda de discussões para se pensar em uma proposta diferente de escola, a qual fosse capaz de ajudar no processo de sua luta principal, na vida dos acampamentos e assentamentos e pela qual valesse sua luta. Nos questionamentos iniciais, o debate central parecia ser em torno da "escola que queremos", "qual a escola necessária?", ou seja, que modelo de escola e proposta pedagógica se ajustava ao contexto do MST e que poderia ajudar atingir seus objetivos. No entanto, durante o processo e o amadurecimento das discussões no decorrer dos anos, percebeu-se a necessidade de trabalhar na postura dos educadores, alterar a escola como um todo dentro do seu próprio contexto, tornando-a acolhedora, sensível pedagogicamente às demandas, aberta ao movimento social e estar em si em constante movimento. Desta forma a escola muda seus sujeitos e é mudada ao mesmo tempo.

Conforme consta no Relatório Escola Itinerante (1997) em 1996, no Rio Grande do Sul foi aprovada a chamada Escola Itinerante dos Acampamentos, com estrutura e proposta física e pedagogicamente criada para acolher assentados e acampados do Movimento dos Trabalhadores Rurais Sem Terra em movimento. Foram 17 anos de luta para a conquista de um direito fundamental e por uma escola que hoje é garantida pela Constituição: uma escola que deve ajustar-se em forma, conteúdo aos seus educandos e não o contrário.

A construção de uma escola diferente dentro da trajetória do MST passa de um direito a um dever, visando transformar a base da sociedade, os su- 
jeitos transformadores de uma futura realidade social, mais justa e digna para todos. Igualando a luta do MST pela educação para todos a sua própria luta pela reforma agrária que também deveria ser uma luta de todos.

A conquista da educação no campo, nos moldes de uma escola que contemplasse todos os aspectos do meio rural, proporcionando às pessoas que ali vivem sua melhoria de condição social e sua valorização é recente na histó ria da educação brasileira. Como vimos às reflexões sobre a importância de um ensino voltado as características singulares do campo e que se adequassem aos movimentos que ansiavam por tal falto, se intensificaram desde a criação do MST na década de 1980. No entanto, somente a partir de 1996, com a nova Lei de Diretrizes e Bases para Educação (LDB), deixou-se de tratar a educação do campo como uma extensão do ensino da cidade, assumindo características que atendessem a realidade camponesa.

[...] uma educação básica do campo voltada aos interesses e ao desenvolvimento sociocultural e econômico dos povos que habitam e trabaIham no campo, atendendo as suas diferenças históricas e culturais, para que vivam com dignidade e que, organizados, resistam contra a expulsão e a expropriação [...] (KOLLING; NERY; MOLINA 1999, p. 28-29).

Após a LDB/1996 fomentou-se o debate a respeito da temática, uma vez que amparada por uma legislação vigente e atualizada, dedicou-se mais atenção a esta modalidade de educação e propor as bases e rumos para o ensino no campo.

Em 1998 organizou-se a Primeira Conferência Nacional "Por Uma Educação Básica no Campo" com participação do MST, da Conferência Nacional dos Bispos do Brasil (CNBB), da Organização das Nações Unidas para a Educação, a Ciência e a Cultura (UNESCO), do Fundo das Nações Unidas para a Infância (UNICEF) e da Universidade de Brasília (UnB), assim como posteriormente delimitou-se as Diretrizes Operacionais para a Educação Básica nas Escolas de Campo. A escola do campo passou a ser debatida visando a sua especificidade, considerando sua complexidade social e geográfica e consolidando-a como um 
modelo de escola alternativo aos moldes estruturais e pedagógicos tradicionais. No documento referido, em seu Artigo $2^{\circ}$, consta:

A identidade da escola do campo é definida pela sua vinculação às questões inerentes à sua realidade, ancorando-se na temporalidade e saberes próprios dos estudantes, na memória coletiva que sinaliza futuros, na rede de ciência e tecnologia disponível na sociedade e nos movimentos sociais em defesa de projetos que associem as soluções exigidas por essas questões à qualidade social da vida coletiva no país (BRASIL, 2001, p. 41).

O MST por sua vez, como parte de todo este processo construtivo de uma escola do campo para o campo, reinterpreta a educação do campo, buscando sincronizá-la a sua realidade, ideologias e necessidades de seus sujeitos. Exaltando sua visão de educação não como a rotina de atividades dentro de uma escola e a importância de uma escola que vivencia a realidade do movimento e a transforma em processo educativo.

O MST tem uma pedagogia. A Pedagogia do MST é o jeito através do qual o Movimento historicamente vem formando o sujeito social de nome Sem Terra e que no dia a dia educa as pessoas que dele fazem parte. E o princípio educativo principal dessa pedagogia é o próprio movimento. É para esta pedagogia, para este movimento pedagógico que precisamos olhar para compreender e fazer avançar nossas experiências de educação e de escola.

\begin{abstract}
A pedagogia do MST é mais do que uma proposta. É uma prática viva, em movimento. É desta prática que vamos extraindo as lições para as propostas pedagógicas de nossas escolas, nosso curso, e também para refletirmos sobre o que seria uma proposta ou um projeto popular de educação para o Brasil (MST, 2001, p. 19).
\end{abstract}

Dentro desta perspectiva e por meio do Departamento de Educação, o MST, delimitou seus princípios filosóficos e pedagógicos, visando reinterpretar os projetos de educação no campo e praticar projetos efetivamente voltados à 
realidade de seus acampamentos e assentamentos. Publicados no Caderno de Educação número 8, p. 16, ano de 1996, são respectivamente, os seguintes:

Princípios filosóficos:

1) Educação para a transformação social: educação de classe, massiva, organicamente vinculada ao movimento social, aberta ao mundo para a ação e aberta para o novo;

2) Educação para o trabalho e a cooperação;

3) Educação voltada para as várias dimensões da pessoa humana;

4) Educação com/para valores humanistas e socialistas;

5) Educação como um processo permanente de formação/transformação humana;

Princípios pedagógicos:

1) Relação entre teoria e prática;

2) Combinação metodológica entre processo de ensino e de capacitação;

3) A realidade como base da produção do conhecimento;

4) Conteúdos formativos socialmente úteis;

5) Educação para o trabalho e pelo trabalho;

6) Vínculo orgânico entre processos educativos e processos políticos;

7) Vínculo orgânico entre processos educativos e processos econômicos;

8) Vínculo orgânico entre educação e cultura;

9) Gestão democrática;

10) Auto-organização dos/das estudantes;

11) Criação de coletivos pedagógicos e formação permanente dos educadores/das educadoras;

12) Atitude e habilidades de pesquisa;

13) Combinação entre processos pedagógicos coletivos e individuais;

Ao tratar da educação básica no campo, a LDB/1996 (Lei de Diretrizes e Bases da Educação), em seu artigo 28, lança mão de adaptações tanto no que se refere aos conteúdos e na metodologia de ensino. Desta forma os princípios pedagógicos e os princípios filosóficos propostos pelo MST não ferem os dispositivos da lei. 
Art. 28: Na oferta da educação básica para a população rural, os sistemas de ensino promoverão as adaptações necessárias à sua adequação às peculiaridades da vida rural, e de cada região, especialmente:

1 - conteúdos curriculares e metodologias apropriadas às reais necessidades e interesses dos alunos da zona rural;

II - organização escolar própria, incluindo adequação do calendário às fases do ciclo agrícola e às condições climáticas;

III - adequação à natureza do trabalho na zona rural (BRASIL, 1996, p. 16).

Traçados tais embasamentos teóricos para as escolas no campo, reafirmados pela LDB e após anos de processo construtivo, o passo seguinte foi repensar o currículo, de acordo com o modelo diferenciado proposto e distante até onde necessário da prática das escolas urbanas.

No campo da práxis, a preocupação fundamental do MST é a valorização da cultura dos grupos sociais que vivem no campo e do contexto social o qual estão inseridos como sujeitos, constituindo o espaço escolar não aos estudantes apenas, mas tornando-o um espaço de transformação e desenvolvimento cultural para toda a comunidade. Os Temas Geradores da proposta pedagógica de Paulo Freire vieram de encontro com tais anseios.

[...] temas geradores são assuntos, questões ou problemas tirados da realidade das crianças e da sua comunidade. Eles permitem direcionar toda a aprendizagem para a construção de um conhecimento concreto e com sentido real, tanto para as crianças como para a comunidade. São estes temas que vão determinar a escolha dos conteúdos, a metodologia de trabalho em sala de aula, o tipo de avaliação [...] (MST, 1992, p. 8).

Para Freire (2002), o ensino precisa gerar a capacidade de ler, apreender e transformar situações marcadas pela exploração, negligência, discriminação, entre tantos outros problemas sociais existentes em nosso meio. Deste modo, o autor nos ressalta que todo processo de aprendizagem deve partir da realidade próxima do aluno por meio da investigação da mesma. 
Os temas geradores partem do estudo da realidade local em consonância para com o estudo da realidade regional, nacional e internacional, ou seja, é partir da parte para se entender o todo. Essa ação direta do aluno na construção de seu conhecimento é bastante explorada por Freire (1999, p. 51), o autor afirma que:

A partir das relações do homem com a realidade, resultantes de estar com ela e de estar nela, pelos atos de criação, recriação e decisão, vai ele dinamizando seu mundo. Vai dominando a realidade. Vai humanizando a. Vai acrescentando a ela algo de que ele mesmo é fazedor. Vai temporalizando os espaços geográficos. Faz cultura. (FREIRE, 1999, p. 51)

Os procedimentos metodológicos por sua vez, baseiam-se em uma metodologia a qual como nos explica Oliveira: [...] deve ser aquela que parte da prática do aluno numa relação prática-teoria-prática, pois o aluno precisa saber para que serve o conteúdo que está estudando (OLIVEIRA, 2006, p. 89).

O papel do educador, nesta proposta deve ser o de facilitador, ou seja, de agente que crie as condições necessárias para a fácil aprendizagem dos alunos, proporcionando que os mesmos utilizem neste processo os seus próprios conhecimentos prévios e mediador da relação entre estudantes, escola e comunidade. Tal prática só é possível devido às concepções curriculares propostas pelo MST que organizam o processo educativo e desempenham um papel fundamental e direcionador as escolas no campo de acordo com sua realidade, organizadas por temas geradores.

Tais concepções descritas nos permite visualizar claramente que para o Movimento dos Trabalhadores Rurais Sem Terra, a educação não significa apenas transferir conhecimentos; reafirmando a sua história de luta pela conquista da educação para assentados e acampados e os convocando a se reconhecerem sujeitos sem-terra, rompendo as cercas das desigualdades sociais e do analfabetismo e utilizando a educação como instrumento para se alcançar a reforma agrária.

Não seria, porém, com essa educação desvinculada da vida, centrada na palavra, em que é altamente rica, mas na palavra 'milagrosamente' esva- 
ziada da realidade que deveria apresentar, pobre de atividades com que o educando ganhe a experiência do fazer, que desenvolveríamos no brasileiro a criticidade de sua consciência indispensável à nossa democratização. (FREIRE, 1999, p. 102)

Destaca-se como último ponto e não menos fundamental em toda esta busca por uma escola do campo efetivamente voltada para a realidade rural, a qualificação de profissionais para atuarem como educadores em assentamentos e acampamentos do MST, principalmente no Ensino Fundamental e Educação para Jovens e Adultos. Recorrendo a parcerias, principalmente a instituições de ensino superior, o movimento preocupa-se em preparar os seus professores para atuarem em suas escolas, cujo sistema de ensino vai além do convencional, os capacitando em cursos rotulados de "Pedagogia da Terra".

Embora a legislação atual reconheça a legitimidade desta proposta, o Estado não garante todas as condições para que a mesma ocorra, sendo seu percurso marcado pela negligência governamental, retaliações por instituições privadas e internacionais e discriminação por grupos políticos e parcela da sociedade. O MST entende que a reforma agrária não se limita a conquista de um pedaço de terra e seu projeto de educação emancipadora e critica segue marcado pela alfabetização e pela conscientização de um grande grupo social que encontrou na escola um poderoso suporte para reconquista da cidadania, da luta contra a desigualdade e exclusão social.

\section{Considerações finais}

Devemos situar o nascimento da escola dentro do contexto de apropriação da educação como instrumento de manutenção do poder e hegemonia do capital. Nagel (2010) destaca que o resgate da função da escola estaria exclusivamente na dependência de um movimento social que pudesse contrariar, contrapor-se ou dimensionar as contradições dos princípios educativos que a movem hoje. Sendo assim, uma das perspectivas de se redesenhar a função social da escola atualmente se encontram em pedagogias contra hegemônicas, que nascem das falhas, lacunas de sistemas vigentes. A autora ressalta que 
[...] todo e qualquer processo educativo proposto, ou encaminhado com o objetivo de mudanças nas relações sociais, jamais ofereceu garantias, ou certezas antecipadas, de como seria a nova sociedade. As propostas inovadoras, sempre contrárias à forma hegemônica existente, sustentaram-se, apenas, no exame da realidade em suas limitações, em suas faIhas, vícios ou lacunas que exigiam, consequentemente, ações intencionais para a modificação do concreto observado. (NAGEL, 2010, p. 56)

Uma educação emancipadora não se desenvolve sem o anseio por ela, sem que os sujeitos tenham a consciência de sua importância e a lucidez de seus contextos sociais e por meio dele pensem propostas contra-hegemônicas para transformá-lo. Desta forma, se a cultura mercantilizada anula os sujeitos e Ihes diminuem a uma inutilidade social, exaltando a individualidade e o desejo de consumo, potencializado pelas novas tecnologias, devemos por meio da educação modificar as formas comportamentais existentes e a formação dos sujeitos, atribuindo Ihes uma identidade social pela qual ousem lutar.

Em suma, resistindo e enfrentando o modelo de educação preestabelecido pelo Estado e pelas políticas educacionais hegemônicas, o MST defende e implantou uma educação voltada para realidade do seu alunato, estabelecendo relações entre teoria e prática e apropriando-se de princípios de cooperação e humanistas, a fim de despertar neste aluno uma consciência crítica sobre sua realidade, tornando-os cidadãos capazes de transformá-la.

Este processo de ocupação da escola pelo MST redesenhou as concepções de ambiente escolar, da escola no campo e das instituições de ensino inseridas na dinâmica de movimentos sociais e nos faz pensar sobre o papel da educação e da escola no contexto atual.

\section{Referências}

BRASIL. Lei de Diretrizes e Bases da Educação Nacional: Lei no 9.394, de 1996. Brasília, DF: Subsecretaria de Edições Técnicas, 1997. 
BRASIL. Ministério da Educação e Cultura. Conselho Nacional de Educação. Diretrizes operacionais para a educação básica nas escolas de campo: parecer CNE/CEB no 36/2001. Brasília, DF, 2001.

CALDART, Roseli Salete. A Escola do Campo em Movimento. Currículo sem Fronteiras, v.3, n.1, pp.60-81, Jan/Jun 2003.

CARDOSO, Maria Angélica. LARA, Ângela Mara de Barros. Sobre as funções sociais da escola. In: CONGRESSO NACIONAL DE EDUCAÇÃO - EDUCERE - III ENCONTRO SUL BRASILEIRO DE PSICOPEDAGOGIA. 9. 2009, Curitiba. Anais... Curitiba, 2009.

CROCHIK, Jose Leon. O computador no ensino e a limitação da consciência. São Paulo: Casa do Psicólogo, 1998.

CUNHA, L. A. O desenvolvimento meandroso da educação brasileira entre o Estado e o mercado. Educação \& Sociedade, Campinas, v. 28, n. 100, p. 809-829, out. 2007.

FERREIRA ABH. Novo Aurélio Século XXI: o dicionário da língua portuguesa. 3 ed. totalmente rev. e ampl. Rio de Janeiro: Nova Fronteira; 1999.

FREIRE, P. Educação como prática da liberdade. Rio de Janeiro: Paz e Terra, 1999.

FREIRE, P. Pedagogia da autonomia: saberes necessários à prática educativa. 25. ed. São Paulo: Paz e Terra, 2002.

KOLLING, Edgar Jorge; NERY, Israel José; MOLINA, Mônica Castagna (Orgs.). A Educação Básica e o Movimento Social do Campo. Coleção Por Uma Educação Básica do Campo, no 1. Brasília: UnB, 1999. 
MOVIMENTO Como fazer a escola que queremos DOS TRABALHADORES RURAIS SEM TERRA. Caderno de Educação, n. 1. São Paulo, 1992.

MOVIMENTO DOS TRABALHADORES RURAIS SEM TERRA. Caderno de Educação, n. 9: Como fazemos a escola de educação fundamental. Porto Alegre, 2004.

MOVIMENTO DOS TRABALHADORES RURAIS SEM TERRA. Relatório Escola Itinerante. Porto Alegre, Secretaria de Estado da Educação, Departamento Pedagógico, Divisão do Ensino Fundamental e Setor de Educação do MST, 1997.

MOVIMENTO DOS TRABALHADORES RURAIS SEM TERRA. A EDUCAÇÃO DO CAMPO: identidade e políticas públicas, 2002. Boletim de Educação, 2001. Brasil, 1996 e 2002.

NAGEL, Lizia Helena. Condições de educabilidade para uma nova sociedade: reflexões básicas. Germinal: Marxismo e Educação em Debate, v.2, n.2, p. 54-68, 2010. ISSN 2175-5604.

NAGEL, Lizia Helena. Função Social da Escola: desafios e perspectivas. Maringá, PR, 2011. Disponível em: http://ccp.uenp.edu.br/dirposgrad/pos_esp/ 13polpub/bib-lizia.pdf. Acesso em 20 de Novembro de 2019.

OLIVEIRA, Alaíde Paulino Machado de. Ideologia e educação: a proposta pedagógica do MST e as escolas de campo de Querência do Norte-Pr. Maringá, PR, 2006.

PALANGANA, Isilda Campaner. A individualidade no círculo da cultura mercantilizada. In: PALANGANA, Isilda Campaner. Individualidade: afirmação e negação na sociedade capitalista. São Paulo: Plexus/EDUC, 1998. 
VALLE, Ione Ribeiro. O lugar dos saberes escolares na sociologia brasileira da educação. In: Currículo sem Fronteiras, vol. 8, n.1, p. 94-108, jan/jun, 2008. Disponível em: www.curriculosemfronteiras.org. Acesso em 20 de Novembro de 2019.

YOUNG, Michael. Para que servem as escolas. In: Educ. Soc., Campinas, vol. 28, n. 101, p. 1287-1302, set./dez. 2007 